\title{
UNIVERSITYOF
}

FORWARD

THINKING

WESTMINSTER用

WestminsterResearch

http://www.westminster.ac.uk/westminsterresearch

Rethinking gossip and scandal in healthcare organizations

Waddington, $\mathrm{K}$.

This article is ( $)$ Emerald and permission has been granted for this version to appear here http://westminsterresearch.wmin.ac.uk/16933/

Emerald does not grant permission for this article to be further copied/distributed or hosted elsewhere without the express permission from Emerald Group Publishing Limited.

The final, published version in Journal of Health Organization and Management, 30 (6), pp. 810-817, 2016 is available at:

https://dx.doi.org/10.1108/JHOM-03-2016-0053

The WestminsterResearch online digital archive at the University of Westminster aims to make the research output of the University available to a wider audience. Copyright and Moral Rights remain with the authors and/or copyright owners.

Whilst further distribution of specific materials from within this archive is forbidden, you may freely distribute the URL of WestminsterResearch: ((http://westminsterresearch.wmin.ac.uk/)).

In case of abuse or copyright appearing without permission e-mail repository@westminster.ac.uk 


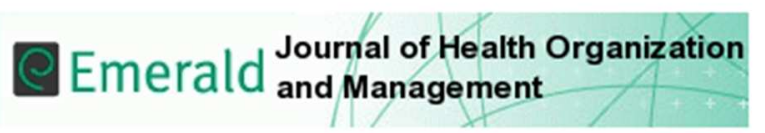

\section{Rethinking gossip and scandal in healthcare organizations}

\begin{tabular}{|r|l|}
\hline Journal: & Journal of Health Organization and Management \\
\hline Manuscript ID & JHOM-03-2016-0053 \\
\hline Manuscript Type: & New Perspectives \\
\hline Keywords: & Communication, Knowledge sharing, Leadership, Safety, Health care \\
\hline \multicolumn{2}{|r}{} \\
\hline
\end{tabular}

\footnotetext{
SCHOLARONE $^{\text {m }}$

Manuscripts
} 
Running head: RETHINKING GOSSIP AND SCANDAL

\begin{abstract}
Purpose - The purpose of this viewpoint paper is to argue that gossip is a neglected aspect of organizational communication and knowledge, and an under-used management resource.

Design/methodology/approach - The paper challenges mainstream managerial assumptions that gossip is trivial or tainted talk which should be discouraged in the workplace. Instead, gossip is re-framed at an organizational level of analysis, which provides the opportunity for relational knowledge about systemic failure and poor practice in healthcare to surface.
\end{abstract}

Findings - Rather than simply viewing gossip as an individual behaviour and interpersonal process, it is claimed that organizational gossip is also a valuable early warning indicator of risk and failure in healthcare systems. There is potentially significant value in re-framing gossip as an aspect of organizational communication and knowledge. If attended to (rather than neglected or silenced) gossip can provide fresh insights into professional practice, decision-making and relational leadership.

Originality/value - This paper offers a provocative challenge to mainstream health organization and management thinking about gossip in the workplace. It offers new ways of thinking to promote patient safety, and prevent the scandals that have plagued healthcare organizations in recent years.

Keywords: Communication, knowledge sharing, leadership, patient safety, health care

Article Classification: Viewpoint 
Gossip is informal, private communication between an individual and a small, selected audience concerning the conduct of absent persons or events. [It] generally contains some element of evaluation or interpretation of the event, but it may be implicit or unstated. Scandal occurs when gossip is elevated into the public arena, when "everyone knows what everyone knows". (Merry, 1984; p275, emphasis added)

\section{Introduction}

$$
\text { Merry's (1984) anthropological work - Rethinking Gossip and Scandal - sets }
$$

the scene for this viewpoint paper, which aims to challenge thinking about gossip in healthcare organizations. In the workplace, gossip is often viewed negatively, as individual and group behaviour to be sanctioned and eliminated (e.g. Nacrelli, 2012). Undoubtedly, malicious and untrue gossip is both unprofessional and unethical because of the potential for harm; yet the absence and neglect of gossip in healthcare management literature is striking. This paper argues viewing gossip in such a negative light has overshadowed the value to be gained in adopting an organizational level of analysis. So rather than tending to see gossip as a problem to be managed or silenced, it can also be seen as a reflection of "the-problem-behind-the-problem", and reframed and as a form of organizational communication and knowledge. As Merry notes, gossip is evaluative, interpretive talk, and this paper argues that gossip can - if attended to rather than silenced or neglected - potentially provide powerful statements and knowledge regarding professional practice, patient safety, collaboration, and leadership. The arguments and thinking in this paper present a contrast to traditional 
historical, philosophical, sociological, business and management literatures surrounding the phenomenon of gossip.

Although gossip, both positive and negative, is at the core of human social relationships and the networks it sustains (Grosser et al., 2010, 2012), traditionally gossip has been seen as women's talk and trivial discourse (Heidegger, 1962; Stewart and Strathern, 2004). Gossip has been cast as the discourse of the powerless and maligned because it is predominantly constituted through informal and unsanctioned interaction. In organizations, such "unofficial" discourse can be disconcerting and threatening to managers because it is almost impossible to control. Gossip undermines formal authority and implicitly challenges managerial power (e.g. see Clegg and van Iterson, 2009). However, such power should not go unchallenged. A recent Special Issue of this journal (2014, Volume 28, Issue 5: Critical Views on Health Care Management) noted that principles of critical management studies are necessary in order to address the darker sides of the care field, and give voice to those in less powerful positions. As Hujala et al. (2014) argued this can result in "redesign of conventional roles and agency of patients, volunteers and professionals and call into question the taken-for-granted understanding of health and social care management" (p. 590). The paper locates workplace gossip in a wider context of critical management studies as a challenge to current managerial thinking and practices.

Over the last decade, high profile scandals and failures in healthcare in the UK National Health Service (NHS) have illustrated the limitations and flaws in current management practices and thinking (e.g. Department of Health [DH], 2005; Francis, 2010; 2013; Subotsky et al., 2010). However as Dixon-Woods et al., (2014) note 
crises, scandals and failures in healthcare systems have occurred as far apart as New Zealand, the Netherlands and the USA. Because of word limit, this viewpoint paper draws upon material from UK public inquiries in order to: (i) rethink the role of gossip as organizational communication and knowledge; and (ii) reflect on the implications for leadership and management.

\section{Gossip and scandal}

From an anthropological perspective, scandal occurs when gossip, and that which "everybody knows", is elevated from the private to the public arena (Gluckman 1963; Merry, 1984). Gluckman's (1963) classic paper Gossip and Scandal illustrated how gossip is core to collective intelligence and solidarity, which can be simultaneously positive and problematic. Managing the tension between the positive and problematic is also core to rethinking gossip and scandal in healthcare organizations. On the one hand, the solidarity afforded by gossip - particularly in highly professionalised, high status groups - can result in elitism and exclusion of other professions and individuals. On the other hand, the activity and process of gossiping imparts a sense of relatedness and kinship, central to Ballatt and Campling's (2011) concept of "intelligent kindness" and call for reform of healthcare culture. Intelligent kindness is an attitude and philosophy that values kinship and kindness, embodying the ability to work with the psychosocial, relational and emotional aspects of healthcare provision. Relentless regulatory and structural NHS reforms, and market-driven approaches to healthcare have spectacularly failed to detect or avert scandals. Failures to attend to promoting connectedness, collaboration and kindness between staff and patients have led to systemic abuses, neglect and 
maltreatment. The "blind eyes" and "deaf ears" of managers and leaders serve to minimize the evidence of problems and/or unintended consequences. There is "active resistance to what is 'known' being directly acknowledged and made properly available for understanding and action” (Ballatt and Campling, 2011, p. 141).

Gossip is important not only in the sense of relatedness and kinship it imparts, but also in its ability to reflect what is "really going on". The Kerr/Haslam Inquiry (DH, 2005) into sexual abuse of patients by psychiatrists showed that knowledge of abuse existed in "informal professional talk between doctors" - in other words gossip. In this instance, failures to attend to gossip, amongst other failings such as nurses who ignored or failed to report patients' concerns, resulted in sustained abuse of vulnerable women for over two decades. This is a manifestation of gossip as a reflection of "problem-behind-the-problem". Gossip is not the problem. The underlying problem is the neglect of gossip as a management resource and topic of research.

\section{The neglect of gossip}

In the UK, the neglect of gossip as a management resource has been drawn into sharp relief in the wake of inquiries into hospital failings and abuses of the relationship between healthcare professionals and patients. The first report (Francis, 2010) into failures at Mid Staffordshire NHS Foundation Trust revealed evidence of neglect and poor care in emergency departments and on general wards. The second report (Francis, 2013) addressed the (in)adequacy of regulatory and supervisory systems, highlighting widespread disengagement in managerial and leadership responsibilities. It is inconceivable and naïve to imagine that such failures and 
inadequacies would not have been gossiped about by front-line practitioners, patients and their families. Staff knew, and talked about, problem areas in Mid Staffordshire:

What is clear is that people talk about what is happening; the grapevine, informal feedback and coffee shop conversations are often the first signals. Top teams must consider what they do with such intelligence. (Harvey, 2011, p. 28)

Yet just like the formal complaints made by families, patients and staff, and reports of regulatory bodies into poor care, concerns expressed informally as gossip and rumour also failed to make an impact. This picture is replicated widely nationally and internationally, where warning signs of failure are similarly discounted, and knowledge about problems becomes fragmented in a culture of silence and secrecy (Dixon-Wood et al., 2014).

Gossip is an inescapable aspect of everyday life in healthcare - and indeed all - organizations. As outlined above, the Kerr/Haslam Inquiry (DH, 2005) illustrated how general practitioners' concerns about the practices of two consultant psychiatrists were expressed as gossip. Professional gossip was euphemistically expressed as "whispers" or "soundings". The Kerr/Haslam Inquiry illustrated how gossip acts as an ethical benchmark with regard to the way institutions approach "soft" information such as gossip, rumour, informal soundings and expressions of concern. Furthermore, the inquiry concluded that conceptualizing gossip as an ethical benchmark "may also be relevant to how the institution sees its responsibilities within society, [and] we can only invite further research" (DH, 2005, p. 683, emphasis added) 
Despite this invitation for further research made over a decade ago, shockingly little empirical work has taken place in healthcare organizations. Funders and scholars of healthcare organization and management have generally failed to acknowledge and engage directly with gossip as a research topic. This in itself is a scandal.

Furthermore, when managers fail to notice, notice but ignore, suppress or scorn the warning signals expressed in gossip they are - metaphorically - driving through a red light. In the railway industry this would represent a "signal passed at danger" and constitute a significant risk to public safety. This paper argues that health management failures to attend to gossip also constitute a significant, and ongoing, risk to patient safety. However recent research (Martin et al. 2015; Millar et al., 2015) into 'soft intelligence', patient safety offers a promising way forward.

\section{Soft intelligence and patient safety}

Martin et al. (2015, p. 19) argue that in addition to formal metrics for monitoring quality of healthcare and patient safety, soft intelligence can be usefully understood as:

The processes and behaviours associated with seeking and interpreting soft data - of the kind that evade easy capture, straightforward classification and simple quantification - to produce forms of knowledge that can provide the basis for intervention.

This in-depth qualitative interview study with 107 senior leaders, managers and clinicians involved in quality and patient safety in the English National Health Service (NHS) highlighted the value of softer forms of data. Millar et al. 's (2015) 
smaller-scale interview study explored key informants' views and perspectives of the dimensions, issues and problems facing hospital boards' oversight of patient safety. Findings suggest intelligence available to boards could be enhanced by "individual members proactively seeking to 'triangulate' hard performance data with different information sources" (p. 9). This chimes with findings from earlier multi-method research into the role of gossip in nursing and healthcare organizations (Waddington, 2005; Waddington and Fletcher, 2005; Waddington, 2014). For example:

"I think you get triangulation of gossip to check accuracy [meaning?]. It's the verification of tittle-tattle, versus the embellishment of a story. If I hear the same piece of information from different sources I think it is more likely to be accurate." (Director of Nursing; in Waddington, 2014, p. 132)

Nevertheless the challenge remains of how to access soft data and transform it into useable, trustworthy knowledge. In Waddington (2014), critical incident analysis is advanced as a means of producing - or eliciting new - knowledge, drawn from: (i) contextualized communicative incidents of gossip; and/or (ii) gossip about a particular organizational incident/event - for example, related to patient safety:

"You can pick on bits of information you know are common knowledge, are still hot gossip about disastrous events in other hospitals, terrible events in our own hospitals." (Clinical Nurse Specialist; in Waddington, 2014, p. 84)

Maccrae (2014) argues "any fleeting uncertainties or doubts regarding patient safety ... need to be seized upon and ruthlessly explored" (cited in Martin et al. 2015, p. 26). The following questions taken from Waddington $(2014$, p. 156) can be used to 
ruthlessly explore incidents of gossip in order to identify underlying issues/areas of concern:

- What organizational issues lie beneath the gossip-related incident/event?

- What is already known about these issues?

- How do we judge the credibility of the content/source of the gossip?

- What needs further verification from other sources?

- What are the risks and ethical implications of not attending to gossip?

Millar et al. (2015) contend that effective board oversight based on trust and intelligence gathering is characterized by leadership styles and behaviours that are attentive to the needs and concerns of both patients and staff. Similarly, this paper contends that rethinking gossip as knowledge, and as a process of organizational communication, re-frames gossip as constitutive of relational, morally-responsible leadership.

\section{Gossip and relational leadership}

Relational leadership emphasises meaningful engagement with others and is seen as non-hierarchical; distributed throughout the organization in relational practices of trust, empathy and collaboration:

This way of theorizing leadership also has practical implications in helping sensitize leaders to the importance of their relationships and to features of conversations and everyday mundane occurrences that can reveal new possibilities for morally-responsible leadership. (Cunliffe and Eriksen, 2011, p. 1425 , emphasis added) 
Gossip is a mundane occurrence and feature of everyday conversations that exemplifies clear moral and ethical aspects for two reasons. Firstly, "toxic gossip" is undoubtedly part of the darker side of care work; there is always potential for harm, for example damage to individual and organizational reputations. Secondly however, there is also the risk associated with the "willful blindness and deafness" of not acting on knowledge about poor practice that is communicated as gossip. Therefore this paper contends that the decision to gossip (or not) and the decision as to what action to take (or not) when faced with gossip, are always ethical decisions. Adopting this approach then, arguably gossip can and should be thought of in the context of decision-making, also a neglected area of leadership practice (Fulop and Mark, 2013). Relational leaders create what Shotter (2008, cited in Cunliffe and Eriksen) refers to as two-part corporate responsibility, consisting of interpersonal relationships, and an institutional focus on core ethical issues of care, concern, and respect.

Relational models of leadership are characterized not as individual behaviours but rather as a shared social process, and collective phenomenon, co-created by leaders and followers in context (Fairhurst and Uhl-Bien, 2012). Importantly, Fulop and Mark (2013) argue that in healthcare, the social construction of leadership and "messy context" in which it is practiced are inseparable individual and collective undertakings. This paper claims that gossip is:

- an inevitable part of the "messy context" of healthcare; and yet also

- an under-researched aspect of relational leadership.

The new ideas presented here advocate inclusion of gossip into leadership and 
management research agendas, and discourses around patient safety and quality, as a challenge to current thinking and practice.

\section{Concluding reflections}

The arguments and views presented here go beyond the topic of gossip alone, and have been set within a broader context of critical management and the need for reform in the culture of healthcare (Ballatt and Campling, 2011; Hujala et al., 2014). The paper concludes by looking to the future and making some provocations and predictions. Without a change in thinking, scandals, unnecessary deaths and human suffering will continue. For example, see the recently reported independent review (Mazars, 2015) highlighting failures of a NHS Foundation Trust, set up to investigate and learn from the deaths of people receiving care from their Learning Disability and Mental Health Services. There will be more articles such as the one by Rogers (2015) exploring the absence of care in "care-less" spaces and systems that should be more "care-full" (p. 1440). Management and organizational journals will continue to publish papers and Special Issues debating, reflecting, and reporting on research into "what went wrong" in healthcare failures and scandals. New leadership paradigms will emerge, but without fresh thinking, that which "everybody knows" about poor quality care and threats to patient safety will remain hidden from public view until it is too late.

A recent Special Issue of Human Resource Management (2015, Issue 54, Number 5) entitled "Human Resource Management in Health Care and Elderly Care" addressed the question (among others): What might be the impact of HRM on 
performance (e.g., quality of patient/client care, patient/client safety) at the individual and organizational level within care organizations? Unsurprisingly organizational gossip did not feature in any of the papers, although Cooke and Bartram (2015, p. 718) concluded that:

There is growing evidence that hospitals have been unsuccessful in achieving acknowledged best practice in quality of patient care and safety ... Research suggests that at the core of the quality challenge lies a lack of effective leadership.

Importantly then, with fresh thinking about gossip as organizational communication and knowledge, new avenues of research begin to open up. This paper has argued that there is a compelling case for including attention to gossip in future research agendas and theorizing around relational leadership. Organizational ethnography, discourse analysis and further case study analysis of empirical material from public inquiries offer promising ways forward (see Carmel, 2011; Fairhurst and Uhl-Bier, 2012; van Iterson and Clegg, 2008). Rather than thinking about gossip as a problem to be managed, gossip needs to be seen and heard as a reflection of the "problem-behind-the-problem". The inevitable tension between the problematic and the positive sides of gossip needs to be surfaced and managed. This will enable organizational gossip to be re-framed as a potentially valuable early warning indicator of risk and failure in healthcare systems and aspect of morally-responsible relational leadership. 


\section{References}

Ballatt, J. and Campling, P. (2011), Intelligent Kindness: Reforming the Culture of Healthcare, RPsych Publications, London.

Carmel, S. (2011), "Social access in the workplace: are ethnographers gossips?", Work, Employment \& Society, Vol. 25, no. 3, 551-560.

Clegg, S. R. and van Iterson, A. (2009), "Dishing the dirt: gossiping in organisations", Culture and Organisation, Vol. 15, Nos. 3-4, pp. 275-289.

Cooke, F. L. and Bartram, T. (2015), “Guest editors' introduction: human resource management in health care and elderly care: current challenges and toward a research agenda, Human Resource Management, Vol.54, No.5, pp. 711-735.

Cunliffe, A. L. and Erikson, M. (2011), "Relational leadership”, Human Relations, Vol. 64, No. 11, pp. 1425-1449.

Department of Health, (DH) (2005), The Kerr/Haslam Inquiry, The Stationery Office, London.

Dixon-Woods, M., Baker, R., Charles, K., et al. (2014), "Culture and behaviour in the English National Health Service: overview of lessons from a large multimethod study", BMJ Qual Saf, Vol. 23, pp.106-115.

Fairhurst, G. T. and Uhl-Bien, M. (2012), “Organizational discourse analysis (ODA): examining leadership as a relational process”, Leadership Quarterly, Vol. 23, pp. 1043-1062.

Francis, R. (2010), Independent Inquiry into Care Provided by Mid Staffordshire NHS Foundation Trust January 2005-March 30 2009, The Stationery Office, London. 
Francis, R. (2013) Report of the Mid Staffordshire NHS Foundation Trust Public Inquiry, The Stationery Office, London.

Fulop, L, (2012), "Leadership, clinician managers and a thing called 'hybridity"”, Journal of Health Organization and Management, Vol. 26, No. 5, pp. 578604.

Fulop, L. and Mark, A. (2013). "Relational leadership, decision-making and the messiness of context in healthcare”, Leadership, Vol. 9, No. 2, pp. 254-277.

Gluckman, M. (1963), “Gossip and scandal”, Current Anthropology, Vol. 4, No. 3, pp. 307-316.

Grosser, T. J., Lopez-Kidwell, V. and Labianca, G. (2010), “A social network analysis of positive and negative gossip in organisational life", Group \& Organization Management, Vol. 35, pp. 177-212.

Grosser, T. J., Lopez-Kidwell, V., Labianca, G. and Ellwardt, L, (2012), “Hearing it through the grapevine: positive and negative workplace gossip", Organizational Dynamics, Vol. 41, pp. 52-61.

Harvey, S. (2011), Report from the Forward Look Seminars, available at: http://webarchive.nationalarchives.gov.uk/20150407084003/http://www.midst affspublicinquiry.com/sites/default/files/uploads/Report_from_Forward_Look _Seminars_-_tagged_for_website.pdf (accessed 5th January 2016).

Heidegger, M. (1962), Being and Time, Harper \& Row, New York, NY.

Hujala, A, Laulainen, S. and Lindberg, K. (2014), "Powerless positions, silenced voices? - critical views on health and social care management", Journal of Health Organization and Management, Vol. 28, No. 5, pp. 590-601. 
Martin, G. P., McKee, L. and Dixon-Woods, M. (2015), "Beyond metrics? utilizing 'soft intelligence' for healthcare quality and safety", Social Science \& Medicine, Vol. 142, pp. 19-26.

Mazars (2015), Independent Review of Deaths of People With a Learning Disability or Mental Health Problem in Contact with Southern Health NHS Foundation Trust April 2011 to March, available at: https://www.england.nhs.uk/south/wpcontent/uploads/sites/6/2015/12/mazars-rep.pdf (accessed 5th January 2016).

Merry, S. E. (1984), "Rethinking gossip and scandal”, in Black, D. (Ed.), Toward a General Theory of Social Control, Academic Press, New York, NY, pp. 271302.

Millar, R., Freeman, T. and Mannion, R. (2015), "Hospital board oversight of quality and safety: a stakeholder analysis exploring the role of trust and intelligence", BMC Health Services Research, 15, DOI 10.1186/s12913-015-0771-x

Nacrelli, T. (2012), Effective Management of Workplace Gossip, Center for Competitive Management, Jersey City, NJ.

Rogers, C. (2015), "Who gives a damn about intellectually disabled people and their families? Care-less spaces personified in the case of LB", Disability \& Society, Vol. 30, No. 9, pp. 1439-1443.

Stewart, P. J. and Strathern, A. (2004), Witchcraft, Sorcery, Rumors and Gossip, Cambridge University Press, New York, NY.

Subotsky, F. (2010), "Psychiatry: responding to the Kerr/Haslam Inquiry", in Subotsky, F., Bewley, S. and Crowe, M. (Eds.), Abuse of the Doctor-Patient Relationship, RCPsych Publications, London, pp. 64-77. 
van Iterson, A. and Clegg, S. R. (2008), “The politics of gossip and denial in interorganisational relations", Human Relations, Vol. 61, No. 8, pp. 11171137.

Waddington, K. (2005), "Using diaries to explore the characteristics of work-related gossip: methodological considerations from exploratory, multimethod research", Journal of Occupational and Organizational Psychology, Vol. 78, No. 2, pp. 221-236.

Waddington, K. and Fletcher, C. (2005), “Gossip and emotion in nursing and healthcare organisations", Journal of Health, Organisation and Management, Vol. 19, No. 4/5, pp. $378-394$.

Waddington, K. (2014), Gossip and Organizations, Routledge, New York and Abingdon. 